\title{
Mitochondrial ferritin is a functional iron-storage protein in cucumber (Cucumis sativus) roots
}

\author{
Gianpiero Vigani ${ }^{1}$, Delia Tarantino ${ }^{2}$ and Irene Murgia ${ }^{2 *}$ \\ ${ }^{1}$ Dipartimento di Scienze Agrarie e Ambientali - Produzione, Territorio, Agroenergia, Università degli Studi di Milano, Milano, Italy \\ 2 Dipartimento di Bioscienze, Università degli Studi di Milano, Milano, Italy
}

\author{
Edited by: \\ Graziano Zocchi, Università degli \\ Studi di Milano, Italy \\ Reviewed by: \\ Luigi Palmieri, Università degli Studi \\ di Bari Aldo Moro, Italy \\ Francisco J. Romera, University of \\ Cordoba, Spain \\ *Correspondence: \\ Irene Murgia, Dipartimento di \\ Bioscienze, Università degli Studi di \\ Milano, Via Celoria 26, 20133 \\ Milano, Italy \\ e-mail:irene.murgia@unimi.it
}

In plants, intracellular Fe trafficking must satisfy chloroplasts' and mitochondrial demands for $\mathrm{Fe}$ without allowing its accumulation in the organelles in dangerous redox-active forms. Protein ferritin is involved in such homeostatic control, however its functional role in mitochondria, differently from its role in chloroplasts, is still matter of debate. To test ferritin functionality as a 24-mer Fe-storage complex in mitochondria, cucumber seedlings were grown under different conditions of Fe supply (excess, control, deficiency) and mitochondria were purified from the roots. A ferritin monomer of around $25 \mathrm{KDa}$ was detected by SDS-PAGE in Fe-excess root mitochondria, corresponding to the annotated Csa5M215130/XP_004163524 protein: such a monomer is barely detectable in the control mitochondria and not at all in the Fe-deficient ones. Correspondingly, the ferritin 24-mer complex is abundant in root mitochondria from Fe-excess plants and it stores $\mathrm{Fe}$ as $\mathrm{Fe}(\mathrm{III})$ : such a complex is also detectable, though to a much smaller extent, in control mitochondria, but not in Fe-deficient ones. Cucumber ferritin Csa5M215130/XP_004163524 is therefore a functional Fe(III)-store in root mitochondria and its abundance is dependent on the Fe nutritional status of the plant.

Keywords: Cucumis sativus, ferritin, iron homeostasis, iron-storage protein, mitochondria, micronutrients, $\mathrm{O}_{2}$ consumption, roots

\section{INTRODUCTION}

The detailed understanding of molecular mechanisms regulating plant nutrient homeostasis is of the highest priority and represents one of the hundred most relevant questions facing plant research (Grierson et al., 2011). Keeping iron (Fe) homeostasis under control is particularly relevant for plants due to its essential role in many house-keeping cellular functions, but also to its toxicity as catalyst of the Fenton reaction, when in a free form (Winterbourn, 1995; Briat et al., 2010). A picture is now emerging of how the Fe deficiency responses, uptake, transport and distribution to various plant organs, together with its intracellular trafficking and storage, are finely tuned on the availability of soluble Fe in the soil by a complex net of signal transduction pathways (Vigani et al., 2009; Murgia et al., 2009; Conte and Walker, 2011; Ramirez et al., 2011; Kobayashi and Nishizawa, 2012; Vigani et al., 2013a,b; Thomine and Vert, 2013).

The intra-organellar partitioning of Fe under various nutritional conditions is intriguing: the question of whether modifications of mitochondrial and chloroplastic Fe metabolism, in response to alteration in the plant $\mathrm{Fe}$ status, represent a source of retrograde signals necessary to regulate the nuclear gene expression, has been posed (Vigani et al., 2013a). For that, metabolic changes in organelles occurring under various conditions of Fe supply should be documented in detail (Vigani et al., 2013a). Investigation of mitochondria from roots is particularly attractive, since the lack of photosynthetically active chloroplasts might reduce the complexity of the retrograde signals involved.
Moreover, roots are directly involved in uptake of Fe from soil and their mitochondria provide chemical energy for such a process.

An extra layer of complexity involving plant Fe nutrition is given by the necessity to prevent $\mathrm{Fe}$ accumulation in dangerous, redox-active forms, in the organelles as well as in the cytosol. Ferritin protein, by forming a 24-mer cage-like structure able to store $\mathrm{Fe}$ in a safe, bioavailable form, is involved in such intracellular control of Fe trafficking and homeostasis, in both plant and animal cells (Arosio et al., 2009; Briat et al., 2009). In plants, ferritin is targeted to chloroplasts (Briat et al., 2009) but its localization to mitochondria has been also documented in Arabidopsis and in pea (Zancani et al., 2004; Tarantino et al., 2010a,b).

The characterization of Arabidopsis atfer4 mutants knock-out for the ferritin isoform, targeted also to mitochondria (Tarantino et al., 2010a,b), posed the question of whether the role of the mitochondrial-targeted AtFER4 is a sort of ancestral relict, replaced by other still unknown regulatory mechanisms of $\mathrm{Fe}$ homeostasis, during the evolution to green plants. On the other side, a relevant role of human mitochondrial ferritin (Levi et al., 2001) as protectant against oxidative stress in various cell types (Campanella et al., 2009; Wang et al., 2011) but also in improving respiratory function in yeast mutants deficient in [Fe-S] cluster biogenesis (Sutak et al., 2012), is emerging.

Taken together, this evidence prompted us to investigate whether ferritin is functional in the mitochondria of cucumber (Cucumis sativus) roots, that is, if it can truly store Fe(III), as a 24-mer complex. 


\section{MATERIALS AND METHODS \\ PLANT GROWTH CONDITIONS AND PURIFICATION OF ROOT MITOCHONDRIA}

Seeds of cucumber (Cucumis sativus L. cv. Marketmore) were sown in Agriperlite, watered with $0.1 \mathrm{mM} \mathrm{CaSO}_{4}$, allowed to germinate in the dark at $26^{\circ} \mathrm{C}$ for $3 \mathrm{~d}$, and then transferred to a nutrient solution with the following composition: $2 \mathrm{mM}$ $\mathrm{Ca}(\mathrm{NO})_{3}, 0.75 \mathrm{mM} \mathrm{K}_{2} \mathrm{SO}_{4}, 0.65 \mathrm{mM} \mathrm{MgSO}_{4}, 0.5 \mathrm{mM} \mathrm{KH}_{2} \mathrm{PO}_{4}$, $10 \mu \mathrm{M} \mathrm{H}_{3} \mathrm{BO}_{3}, 1 \mu \mathrm{M} \mathrm{MnSO}_{4}, 0.5 \mu \mathrm{M} \mathrm{CuSO}_{4}, 0.5 \mu \mathrm{M} \mathrm{ZnSO}$, $0.05 \mu \mathrm{M}\left(\mathrm{NH}_{4}\right) \mathrm{Mo}_{7} \mathrm{O}_{24}$, and $\mathrm{Fe}(\mathrm{III})$-EDTA at the following concentrations: $0 \mathrm{mM}$ (Fe deficiency), $0.05 \mathrm{mM}$ (Control), $0.5 \mathrm{mM}$ (Fe excess). The $\mathrm{pH}$ was adjusted to 6.0-6.2 with $\mathrm{NaOH}$. Aerated hydroponic cultures were maintained in a growth chamber with

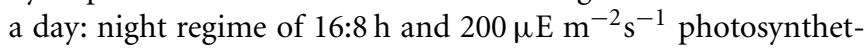
ically active radiation (PAR) at the plant level. The temperature ranged from $18^{\circ} \mathrm{C}$ (in the dark) to $24^{\circ} \mathrm{C}$ (in the light).

Mitochondria were purified from cucumber roots according to Balk et al. (1999) and Vigani et al. (2009), with few modifications. 10 days old roots were homogenized with a mortar and pestle in 0.4 M mannitol, $25 \mathrm{mM}$ MOPS pH 7.8, $1 \mathrm{mM}$ EGTA, $8 \mathrm{mM}$ cysteine, and $0.1 \%(\mathrm{w} / \mathrm{v})$ bovine serum albumin (BSA). The filtered homogenized plant material (total extract, TE) was centrifuged $5 \mathrm{~min}$ at $4000 \mathrm{~g}$ and the pellet was used as an enriched plastids fraction $(\mathrm{P})$. The supernatant was re-centrifuged $15 \mathrm{~min}$ at $12,000 \mathrm{~g}$ to pellet mitochondria whereas the supernatant fraction constitutes the so-called PMS (post-mitochondria supernatant fraction). The crude mitochondrial pellet was resuspended in RB buffer (0.4 M mannitol, $10 \mathrm{mM}$ Tricine pH 7.2, $1 \mathrm{mM}$ EGTA) and lightly homogenized with a potter; mitochondria were further purified on a 40, 28, and $13.5 \%(\mathrm{v} / \mathrm{v})$ Percoll (Pharmacia) step gradient in RB buffer. The fraction at the $28 / 40 \%$ interface (purified mitochondria) was collected and washed by differential centrifugation in RB buffer.

\section{NATIVE GEL ELECTROPHORESIS AND WESTERN BLOT ANALYSIS}

Purified mitochondrial proteins were loaded on a non-denaturing polyacrylamide gel $(3 \%[\mathrm{w} / \mathrm{v}]$ stacking, $5.5 \%[\mathrm{w} / \mathrm{v}]$ separating) after heating at $65^{\circ} \mathrm{C}$ for $7 \mathrm{~min}$. The gel was run for $5 \mathrm{~h}$ at $25 \mathrm{~mA}$ (on ice); then the gel was rinsed in water and incubated in potassium ferrous cyanide solution [ $2 \% \mathrm{KFe}(\mathrm{II}) \mathrm{CN}, 2 \% \mathrm{HCl}], 1 \mathrm{~h}$ in the dark. The gel was washed four times in $\mathrm{H}_{2} \mathrm{O}, 15$ min each, with gentle shaking and incubated overnight in a diaminobenzidine (DAB) solution $\left(0.05 \% \mathrm{DAB}, 18 \mathrm{mM} \mathrm{H}_{2} \mathrm{O}_{2}\right.$ in $\mathrm{PBS}$ at $\mathrm{pH}$ 7.4) without shaking.

SDS-PAGE was performed according to Vigani et al. (2009) with the following antibodies: spinach anti-Toc33 (Rödiger et al., 2010) at 1:1000 dilution, maize anti-porin (Balk and Leaver, 2001) at 1:2000 dilution, Arabidopsis anti-ATFER1 (Murgia et al., 2007) at 1:2000 and an anti-rabbit conjugated with alkaline phosphatase as secondary antibody. Protein quantification was determined according to Vigani et al. (2009).

\section{RT-PCR}

Roots apices and true second leaves from 10 days old plants grown under Fe-excess were sampled and RNA extracted with Trizol reagent (Gibco). RT-PCR reactions were performed by using Access RT-PCR kit (Promega), 60 ng total RNA/reaction.

\begin{abstract}
Cucsafor 1:5'-CCACCACACACACACACGC-3'
Cucsarev1:5'-ATTGTCTCTGTCAAAGTAGGC-3'

Cucsarev2: 5' -TTGGCCAAACCCTTGAGTGC-3'

Cucsarev3: 5' -CCATTGCAAAAAAAGCATCTCC-3'

Cucsarev4: 5'-GAGCTCCATTGCATATAAGGC-3'
\end{abstract}

For Cucsafor1-Cucsarev1: $1 \mathrm{mM} \mathrm{MgSO}_{4}$ final conc., annealing at $61^{\circ} \mathrm{C}$; for Cucsafor1-Cucsarev2: $1.5 \mathrm{mM} \mathrm{MgSO}_{4}$ final conc., annealing at $61^{\circ} \mathrm{C}$; for Cucsafor1-Cucsarev3: $1.5 \mathrm{mM} \mathrm{MgSO}_{4}$ final conc., annealing at $57-67^{\circ} \mathrm{C}$; for Cucsafor1-Cucsarev4: $1 \mathrm{mM}$ $\mathrm{MgSO}_{4}$ final conc., annealing at $61-67^{\circ} \mathrm{C}$.

\section{MISCELLANOUS}

Total Chl, Chla and Chlb content was determined according to Lichtenthaler (1987). Fe content in purified mitochondria was determined by ICP-MS spectroscopy (Variant).

$\mathrm{F}_{0} \mathrm{~F}_{1} \mathrm{ATP}$ synthase and $\mathrm{G} 6 \mathrm{PDH}$ activities were performed according to Camacho-Pereira et al. (2009).

$\mathrm{O}_{2}$ consumption and use of KCN and SHAM (salicylhydroxamic acid) was measured on root apices from 10 days-old plants according to Vigani et al. (2009).

Protein sequence alignment was performed with Multalin version 5.4.1 (Corpet, 1988) at http://multalin.toulouse.inra.fr/ multalin/.

\section{RESULTS}

\section{Fe-DEFICIENT AND Fe-EXCESS ROOT TIPS SHOW AN INCREASE IN THE $\mathrm{O}_{2}$ CONSUMPTION RATES}

Cucumber seedlings were grown in hydroponic medium for 10 days in a complete nutrient solution containing 0,50 , or $500 \mu \mathrm{M}$ Fe(III)-EDTA (Fe deficiency, control, excess) (Figure 1A). Fe deficient plants showed the typical symptoms of chlorosis in leaves, while leaves from both control or Fe excess plants were green; length of root apparatus was reduced in Fe-deficient plants (Figures 1A,B). Accordingly, total Chl content was very low in the Fe-deficient leaves (Figure 1C), while no significant differences in total Chl nor in Chla/Chlb content, could be detected between Fe-excess and control leaves (Figure 1C).

Root tips are the most metabolically active parts of the roots and indeed they are the main site displaying Fe uptake in which Strategy I activities are strongly induced (Landsberg, 1986; Vigani et al., 2012) Both Fe-deficient and Fe-excess root tips show higher $\mathrm{O}_{2}$ consumption rates than control root tips (Figure 1D). Moreover, the addition of KCN and SHAM (inhibitors of the respiratory $\mathrm{O}_{2}$ consumption) did not completely block the $\mathrm{O}_{2}$ consumption, differently from what was observed in control root tips where such inhibitors almost completely abolished it (Figure 1D). Such residual $\mathrm{O}_{2}$ consumption in root tissues of $\mathrm{Fe}$ deficient as well as of Fe-excess plants, not attributable to the mitochondrial respiratory chain activity, has been already described in cucumber (Vigani et al., 2009).

\section{PURITY OF MITOCHONDRIA ISOLATED FROM CUCUMBER ROOTS}

A one step-gradient protocol was applied for purifying mitochondria from seedling roots grown in the different conditions of Fe supply. Since it is well established that ferritin accumulates in plastids of plants grown under Fe-excess, all the different 


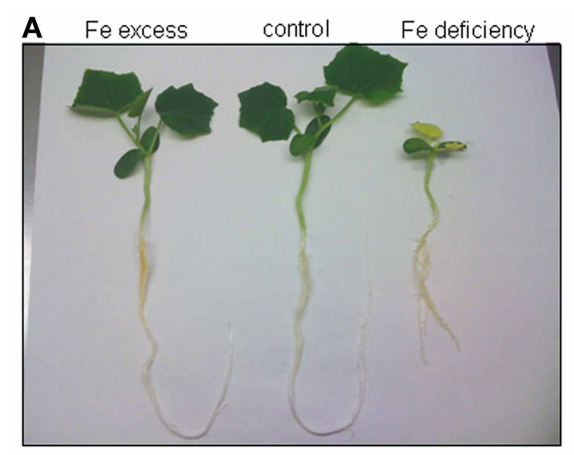

$\mathbf{B}$

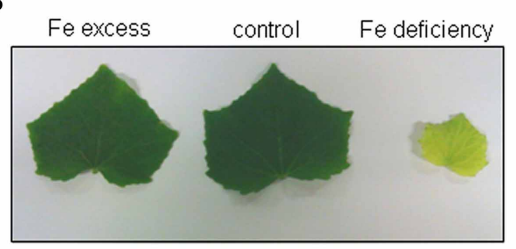

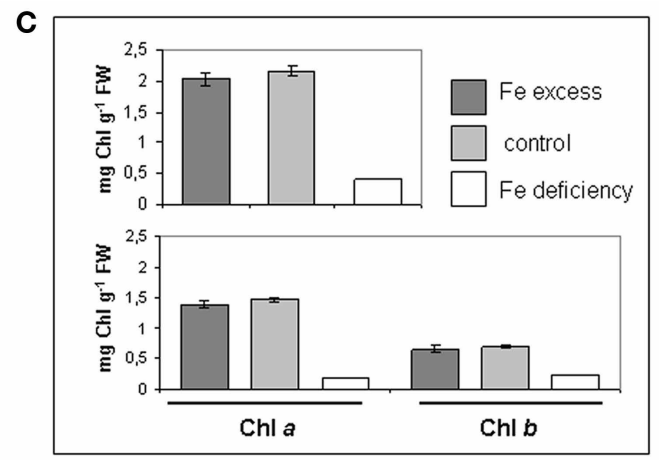

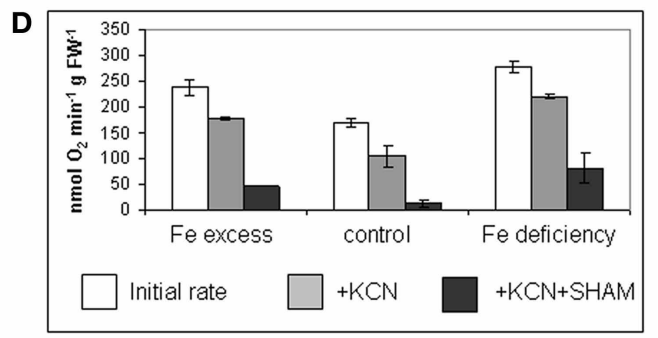

FIGURE 1 | Cucumber seedlings under different conditions of $\mathrm{Fe}$ supply. (A) 10 days-old cucumber seedlings grown in hydroponic medium containing either $500 \mu \mathrm{M}$ Fe(III)-EDTA (Fe excess), $50 \mu \mathrm{M}$ Fe(III)-EDTA (control), or with no added Fe in the medium (Fe deficiency). (B) Leaves of cucumber seedlings grown as in (A). (C) Chl content ( $\mathrm{mg} \mathrm{g}^{-1} \mathrm{FW}$ ) of seedlings leaves, grown as in (A); upper panel: total $\mathrm{Chl}$ content; lower

fractions collected during isolation of mitochondria from $\mathrm{Fe}$ excess roots, i.e., the TE, the plastid enriched fraction $(\mathrm{P})$, the purified mitochondria (M) and the post-mitochondrial supernatant (PMS) (Balk et al., 2004) were tested with two different enzymatic assays as well as with different antibodies (in SDSPAGE experiments), in order to exclude any contamination of the purified mitochondrial fractions with intact plastids. Activity of $\mathrm{F}_{0} \mathrm{~F}_{1}$ ATP synthase enzyme, a marker used for mitochondria (Camacho-Pereira et al., 2009) was measured in the four isolated fractions TE, P, M, and PMS (Figure 2A). $\mathrm{F}_{0} \mathrm{~F}_{1}$ ATP synthase activity is highest in the $M$ fraction $\left(0.79 \mathrm{U} \mathrm{mg}^{-1}\right.$ prot), and, as expected, also in the TE fraction $\left(0.56 \mathrm{U} \mathrm{mg}^{-1}\right.$ prot) (Figure 2A). A 40\% reduction of enzyme activity is observed in PMS fraction containing the cytosol $\left(0.35 \mathrm{U} \mathrm{mg}^{-1}\right.$ prot $)$ whereas it is almost undetectable in the $\mathrm{P}$ fraction $\left(0.05 \mathrm{U} \mathrm{mg}^{-1}\right.$ prot) (Figure 2A). Glucose 6 phosphate dehydrogenase (G6PDH) is localized both in cytosol and in the plastids' stroma (CamachoPereira et al., 2009) therefore it can be used as a cytosolic and plastidial enzyme marker; its activity is undetectable in $\mathrm{M}$ fraction (Figure 2B), whereas it is highest in the PMS (8.95 $\mathrm{U} \mathrm{mg}^{-1}$ prot), followed by $\mathrm{P}\left(6.70 \mathrm{U} \mathrm{mg}^{-1}\right.$ prot), and TE (4.20 $\mathrm{U} \mathrm{mg}^{-1}$ prot) (Figure 2B). The two enzyme assays confirmed that the purified mitochondria are not contaminated by the cytosolic fraction nor from integral, undisrupted plastids, since in that case the G6PDH enzymatic activity should have been detected also in the mitochondrial fraction. Furthermore, the plastid marker Toc33 protein (Rödiger et al., 2010) accumulated only in the P fraction
(Figure 2C), whereas porin (Balk and Leaver, 2001) accumulated, as expected, in the $\mathrm{M}$ fraction and, to lesser extent, in the $\mathrm{P}$ fraction (Figure 2C).

\section{A FERRITIN 24-mer COMPLEX ACCUMULATES IN THE ROOT MITOCHONDRIA FROM Fe-EXCESS PLANTS AND IT STORES Fe(III)}

The genome of the Chinese Long cultivar of cucumber (line 9930) was first annotated in 2009 and then reassembled and reannotated (Huang et al., 2009; Li et al., 2011) (www.icugi.org/cgibin/ICuGI/index.cgi). According to that annotation, a unique ferritin protein sequence, named Csa5M215130 (259 aa), is encoded by the cucumber genome (Figure 3). The genome of a North-European cultivar (B10) has been also sequenced (Wóycicki et al., 2011) and again, a unique ferritin gene has been identified, LOC101221012 with three different transcript variants, the protein sequences of which are deposited in the NCBI database: XP_004148174 (259 aa), XP_004163524 identical to Csa5M215130 (259 aa) and XP_004163525 (241 aa) (Figure 3). XP_004148174 and XP_004163524 differ by two aa at position 180-181 (Figure 3), whereas XP_004163525 lacks a 18 aa stretch at position 104 (Figure 3). A further sequencing of the cucumber genome has been made available at Phytozome (http://www.phytozome.net), a comparative hub for plant genome analysis (Goodstein et al., 2012). According to this, the cucumber genome possesses a single ferritin gene Cucsa144440 with its primary transcript coding for a protein identical to Csa5M215130/XP_004163524. 

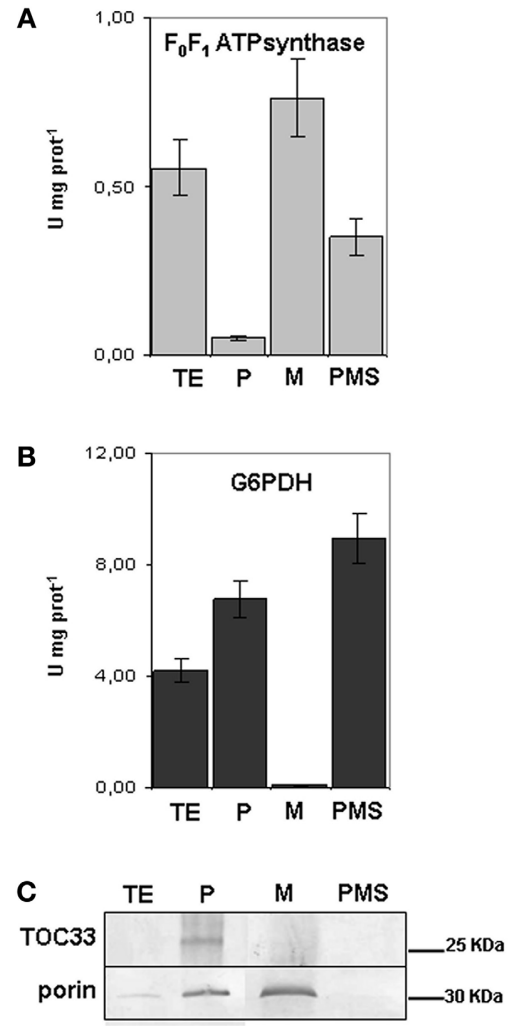

FIGURE 2 | Purity of mitochondria isolated from cucumber roots. (A) $\mathrm{F}_{0} \mathrm{~F}_{1}$ ATPsynthase activity, expressed as Units $\mathrm{mg}^{-1}$ protein in the different fractions obtained during purification of mitochondria: total extract (TE), enriched plastids $(P)$, mitochondria $(M)$ and the post- mitochondria supernatant fraction (PMS). Bars represent the mean values \pm SE from 4 independent samples of 30-50 $\mu \mathrm{g}$ protein each. (B) Glucose 6-phosphate dehydrogenase activity (G6PDH) in TE, P, M and PMS fraction. Bars represent the mean values \pm SE from 4 independent samples of 30-50 $\mu \mathrm{g}$ protein each. (C) SDS-PAGE, followed by western blot analysis, of TE, P, M and PMS fractions; equal protein quantity $(12 \mu \mathrm{g})$ was loaded in each lane.

To investigate ferritin localization and its physiological role in root mitochondria, quantification of Fe content, by ICP-MS analysis, in mitochondria purified from roots of plants grown under different conditions of Fe supply, was first performed.

Total Fe in mitochondria from Fe-excess roots is $718.92 \mathrm{nmol}$ $\mathrm{mg}^{-1}$ prot, more than two-fold higher than in control ones (309.77 $\mathrm{nmol} \mathrm{mg}^{-1}$ prot) (Figure 4A); this result confirms that growth of cucumber plants under Fe-excess treatment is effective in perturbing the Fe content of their mitochondria, beside their function, such as the described increase in $\mathrm{O}_{2}$ consumption (Figure 1D). Total Fe content is, instead, dramatically reduced in mitochondria purified from Fe-deficient plants; nevertheless, such Fe-deficient mitochondria are still able to perform their respiratory function (Figure 1D) thus suggesting that mitochondria are still functional in such stress conditions.

The mitochondria purified from control, Fe-excess or Fedeficient roots were then analyzed by western blot with the Arabidopsis anti-ATFER1 ferritin antibody (Murgia et al., 2007), raised against the 16-aa antigen peptide GVVFQPFEEVKKADL

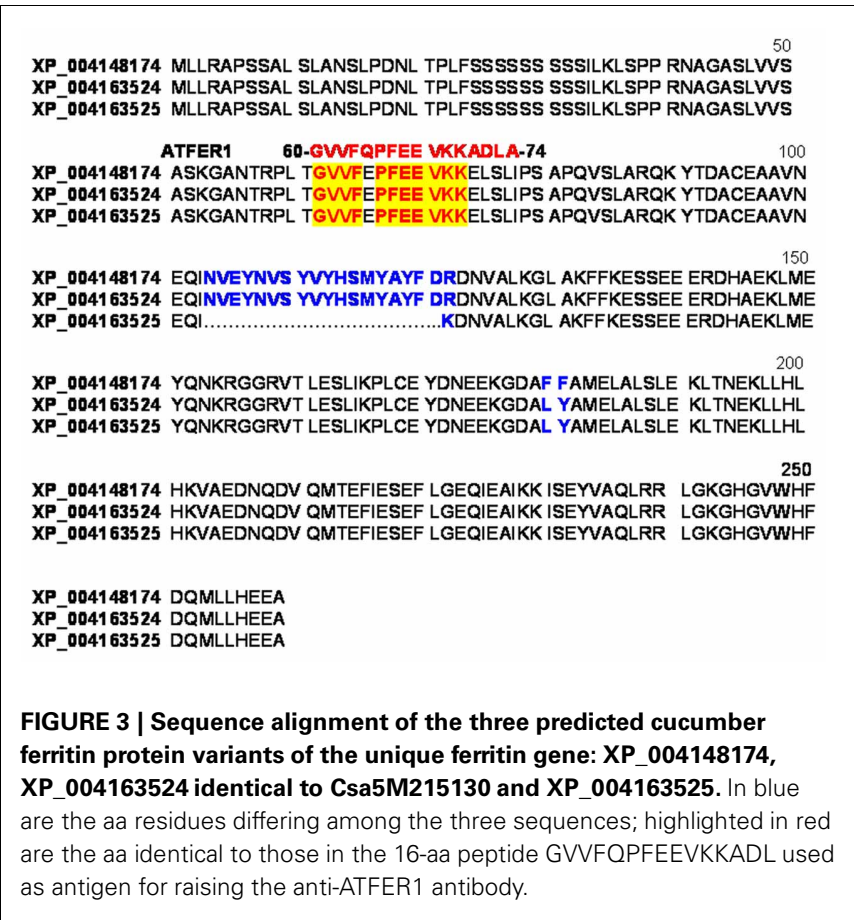

corresponding to aa 60-74 in the Arabidopsis ATFER1 sequence; such an antibody is appropriate for the detection of cucumber ferritin since both Csa5M215130/XP_004163524, as well as XP_004148174 and XP_004163525, would show an 11/16 aa match with such a peptide (Figure 3 ).

As a positive control, crude protein TE from pea seeds (rich in ferritin) was used (Figure 4B); pea ferritin is indeed detected by the anti-ATFER1 antibody (Murgia et al., 2007).

A single band of around $25 \mathrm{KDa}$ could be detected, the accumulation of which is dependent on Fe-content of the mitochondria, being strong in Fe-excess mitochondria, still detectable in control mitochondria and undetectable in Fe-deficient ones (Figure 4B). Equal loading of protein content for each sample was confirmed through hybridization with anti-porin antibody (Figure 4B) (Vigani and Zocchi, 2010).

The Fe-excess, control and Fe-deficient mitochondria, tested above, were also analyzed by native gel electrophoresis followed by Prussian blue staining, which stains $\mathrm{Fe}$ in the oxidized form $\mathrm{Fe}(\mathrm{III})$, and $\mathrm{DAB} / \mathrm{H}_{2} \mathrm{O}_{2}$ enhancement (Luscieti et al., 2010). Recombinant human ferritin 24-mer complex (around $500 \mathrm{kDa}$ ) served as a positive control. A band of higher molecular weight than the recombinant human ferritin complex is clearly detected in Fe-excess mitochondria; such band is fairly weak in control mitochondria and undetectable in Fe-deficient ones (Figure 4C).

Identity of the ferritin detected in Fe-excess mitochondria (Figures 4B,C) could be unambiguously attributed to Csa5M215130/XP_004163524. Indeed, based on gene and predicted coding sequences of XP004163524 (annotated at NCBI as ferritin-3, chloroplast-like, transcript variant 1 (LOC101221012) (Figure 5), of XP004163525 (annotated at NCBI as ferritin-3, chloroplast-like, transcript variant 2) (Figure S1) and of 
A

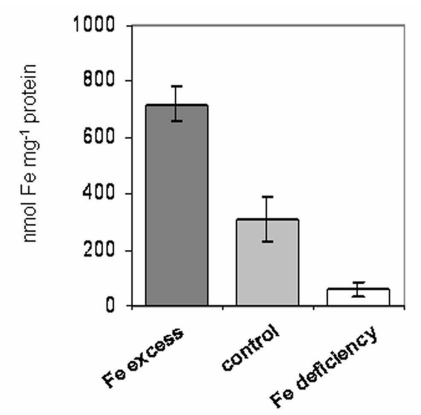

B
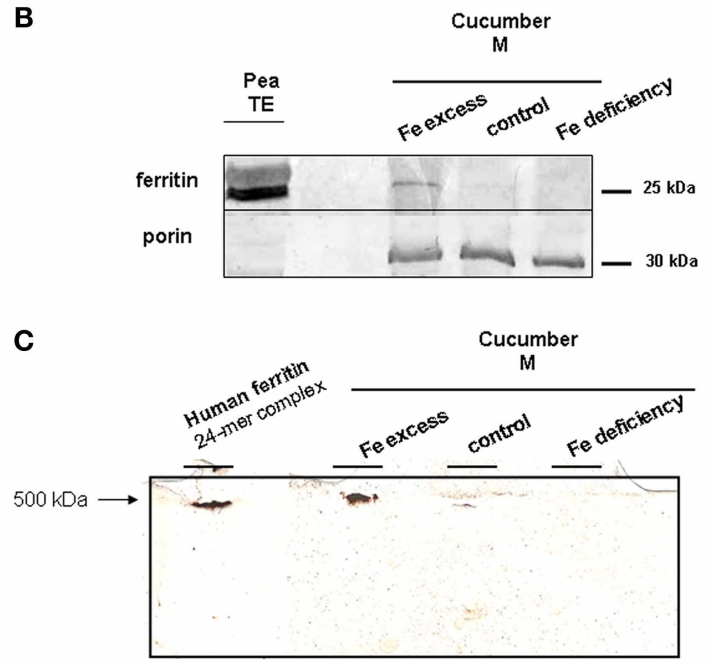

FIGURE 4 | Fe and ferritin content in mitochondria from cucumber roots grown under different conditions of Fe supply. (A) Total Fe content in mitochondria purified from Fe-excess, control, or Fe-deficiency roots, quantified by ICP-MS. Each bar represents the mean value \pm SE from 4 independent samples consisting of 60-200 $\mu \mathrm{g}$ mitochondria each. (B) SDS-PAGE and western blot analysis of mitochondria purified from Fe-excess, control, or Fe-deficiency root. $15 \mu \mathrm{g}$ proteins were loaded in each lane. As positive control, $34 \mu \mathrm{g}$ total extract (TE) from pea seeds, rich in ferritin, has been loaded in leftmost lane. (C) native PAGE analysis, followed by Prussian blue/DAB stain of mitochondria purified from Fe-excess, control or Fe-deficiency root; $40 \mu \mathrm{g}$ proteins were loaded in each lane. As positive control, $48 \mu \mathrm{g}$ proteins recombinant human ferritin consisting of a $24-$ mer of around $500 \mathrm{KDa}$, was also loaded in the far left lane.

XP_004148174 (annotated at NCBI as ferritin-3, chloroplast-like) (Figure S2) five different primers Cucsafor1, Cucsarev1-rev4 were designed for RT-PCR experiments with RNA purified from either roots or leaves from Fe-excess cucumber plants (thus accumulating ferritin). Results show that RT-PCR with the following pairs: Cucsafor1-Cucsarev1 and Cucsafor1-Cucsarev2, amplified, respectively a fragment of 436 and 470 bp (Figure 5B, left panel), as expected from an mRNA coding for XP004163524 (Figure 5A) but not from an mRNA coding for XP004163525 (Figure S1). Moreover, RT-PCR with the Cucsafor1-Cucsarev4 primer pair amplified a fragment of 612 bp (Figure 5B, right panel), expected from an mRNA coding for XP004163524 (Figure 5A) but not from an mRNA coding for XP_004148174 (Figure S2); amplification of such fragment, in roots and in leaves, has been obtained not only at the optimal annealing temperature for that primer pair $\left(61^{\circ} \mathrm{C}\right)$, but also at more stringent conditions, i.e., with annealing temperatures up to $67^{\circ} \mathrm{C}$ (Figure 5B, right panel). Viceversa, RT-PCR with Cucsafor1-Cucsarev3 primer pair (Figure S2) performed with RNA extractions from different roots and leaf samples, could not amplify any fragment expected from the mRNA coding for XP_004148174 (data not shown).

The transcription of a single mRNA coding for cucumber ferritin in roots as well as in green leaves with consequent translation of a unique ferritin protein, strongly suggests that cucumber ferritin is "dual targeted" in both mitochondria and chloroplasts (Carrie and Small, 2013). PSort (http://psort. hgc.jp/form2.html), MitoProtII (http://ihg.gsf.de/ihg/mitoprot. html) and TargetP (http://www.cbs.dtu.dk/services/TargetP/) programs are three widely used bioinformatic tools predicting subcellular localization of a given protein sequence and cleavage site of the corresponding transit peptide (Nakai and Kanehisa, 1991; Claros and Vincens, 1996; Emanuelsson et al., 2007). Such programs, when applied to the three putative protein variants Csa5M215130/XP_004163524, XP_004148174 and XP_004163525, for prediciting the mitochondrial localization, give different results: MitoProtII scores are indeed, respectively: $0.82,0.79,0.80$; PSort scores are 0.47 for all the three sequences whereas TargetP scores are below 0.1 for all the three sequences. The predictions of the cleavage site for the transit peptide are also quite different among the three programs, being of 68 aa with MitoProtII, 32 aa with PSort and 50 aa with TargetP. Variability of such results is not surprising, since it is widely known that such bioinformatic predictors proved extremely problematic for dual targeted proteins (Pujol et al., 2007; Berglund et al., 2009; Carrie and Small, 2013).

A 14 bp Iron Dependent Regulatory Sequence (IDRS) is present in the promoter region of the Arabidopsis AtFerl gene and is responsible for the AtFer 1 transcriptional repression under low Fe supply. On the contrary, Fe treatment releases the IDRSmediated transcriptional repression of the AtFerl gene via a NO-dependent mechanism, and AtFerl ferritin transcript can therefore accumulate (Petit et al., 2001; Murgia et al., 2002; Arnaud et al., 2006).

A 14-bp sequence, $64 \%$ identical to the AtFer1 IDRS, is present in the promoter region of the cucumber ferritin gene LOC101221012/Csa5M215130/Cucsa144440, at position -199 from ATG start (Figure 5A), similarly to what is observed for the AtFer1 IDRS sequence (Petit et al., 2001).

\section{DISCUSSION}

The scientific relevance in focusing on plant nutrients and their homeostasis is not confined to the potential long-term benefits in agriculture: indeed, a better understanding of Fe homeostasis can have positive impacts and can offer new solutions for combatting malnutrition (Grierson et al., 2011). Such knowledge can assist the exploitation of new strategies for the production of plants biofortified for $\mathrm{Fe}$ and for reducing Fe deficiency anaemia, a severe burden for populations in developing countries mostly affecting children and women (Murgia et al., 2012).

Elucidation of the role of mitochondria in plant Fe homeostasis is a challenging issue (Vigani et al., 2013a). Despite the 
A

-93 AATATCCAACTCACAACCTGGCACGAGCTTGACACGCG CTCATCTCCGATTCTCAATCATATCCGTCCACGTCCCTCTTAATCCAACGCCCTT

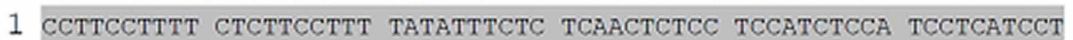

61 CTTCCACCAC ACACACACAC GCACAGTGAC TCTCTCAAAA CCCTCAAAAA ATTTCCATTT

121 CTCCATCATG CTTCTTCGTG CTCCTTCATC TGCTCTCTCC CTCGCTAATT CTCTACCCGA

181 TAATCTCACT CCTCTCTTTT CTTCTTCTTC TTCCTCTTCC TCTTCCATTC TCAAGCTTTC 241 TCCCCCCAGA AACGCTGGCG CTTCGCTCGT TGTCTCAGCC TCCAAAGGCG CCAATACTCG 301 TCCCTTAACG GGAGTGGTTT TTGAGCCTTT TGAGGAGGTT AAGAAGGAGC TTAGTCTTAT

361 TCCCTCTGCT CCTCA.AGTCT CGCTTGCTCG TCAGAAGTAC ACCGATGCTT GTGAGGCTGC 421 GGTTAATGAG CAAATTAAGT GAGTTTTCTT GTTTTCTTTT TTTCTTTTTC CCTTGATTTG 481 GTCTGTTCTC GGGAGGAATT TTGTTTGTGG ATTTTTCTT GGACATCTGT TTTTGAGTTA

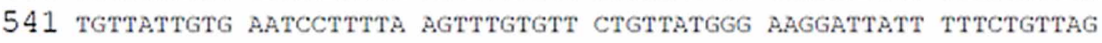
601 TTATCTGATT TTCTTAATTA TGTGATGGAT TGCTTTCATT TCTTGCTGAT TTGAGGTTTA 661 GTGTTTTTTA TCTTTGGTTT GAATATGAAT CTTTATCAGG AAATTTCTTT TTTTCTCTTT 721 TAACGTACAT ATTTTGTTT GAGTTTCCTT GTTGGTATT TTATATGCAT ATGATTCTTT 781 GCATGGAMT TATTTGTAC CTTACAATA AACATGCATA TTTGATTTGA TATTACATTT 841 ATGGTTATAT ATATGAAAC TAACGAGAT GGATTTGATA ACAGTGTTGA ATACAATGTG 901 TCATATGTAT ATCATTCCAT GTATGCCTAC TTTGACAGAG ACAATGTAGC ACTCAAGGGT 961 TTGGCCAAGT GAGTTTTGAT TTTTGGATAT CTTGTCTTAT TTTCAAAAAC CAAATCGAAC 1021 CGTTACTAAG TGGTTTTTTT CCTTATAATT TGTGGAACTT CARAGGTTTT TCAAGGAATC 1081 AAGTGAAGAA GAAAGGGATC ACGCTGAGAA ATTGATGGAA TATCAGGTAG ATAAGTTGCG 1141 AGGAAGGTTG ATTTTGTGTT TTTAGAATTT CTTTTATTGA TTTTGGATCA TTTTGCAGAP 1201 CAAACGAGGT GGGCGAGTGA CATTAGAGTC TTTGATTAAG CCCTTGTGTG AATATGACAA 1261 TGAGGAAAAA GGAGATGCCT TTTTTTTTTT TTAATCTTTT CATTGCTATA TTTATATGA.

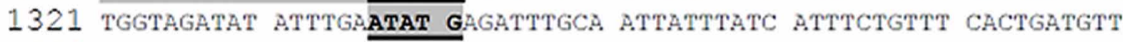
1381 GACTTCCTAA CATCAATGAT AAGGACTTGA ATTTGTGAAA TTATCTGCAT GTTGATTGAT 1441 GTCTTATTCC TAGTTTATAC TTGCATGCTA TARTTCTATA ATTATGTTGT TGATTGTGAC 1501 ATTGAGATGT CTTATGTGTT TTAAATTTA AGCAATGGA CTCGCTTTAT CCCTTGAGAA 1561 GCTAACAAAT GAAAAGTAC TCCACTTGCA CAAGGTAGAG TTTTATTTAT GGCTTTCACA 1621 TTTTTGTTTA GGGTGTTGCT TGAGTTCTGA AGTTGTAGA ATATACTTAT TATGTGCATT 1681 CTCTCTTAGg TGGCTGAAGA TAATCAAGAC GTGCAGATGA CCGAGTTTAT TGAAAGCGA. 1741 TTCTTGGGAG AACAGGTAAC AACGCCTCTG CGAGTGATTG ATTTTAATTA TACTTTGTTG 1801 TCACATAAGC ATAAATATTC TCAATGTTTA AAACTTAACC ATTCTAGATA GAAGCAATCA 1861 AGAAAATCTC AGAGTATGTT GCACAGCTAA GAAGACTAGG CAAGGGACAC GGTAAGGATA 1921 ACAACAATGC CCTCGCCCCC CATTGCCTCT TGGCTTTCGG TTTTCTCGTT CCTAATGTGT 1981 CTCCGGTGGT TAACGATATT CTTTTTGAAA CCTTGTTTTC AGGAGTGTGG CACTTTGATC 2041 AgATGTTGCT TCACGAGGAA GCATAAACAA AGGGATTTGg CTGCATAGAg TAAAAGTTTA 2101 GTGAAATATG AAAATAA.AAT GGTGTCCAGG TTGGATGTGG TTGTTTGGAT TTCTAGTTTT 2161 AGAGGGCAGA TGATGATTTG TGTTAGAATT TTCTGTTGTT AACGTGTTAG TTAATGTTGT 2221 GTTTTGGTTT TCAAAGGTTT ATTTTGATGT TAATGGAAGA TTCTCACTTG TTTTTAATTC 2281 TAAACTAGAC TTTATTTACC CTATTT

B

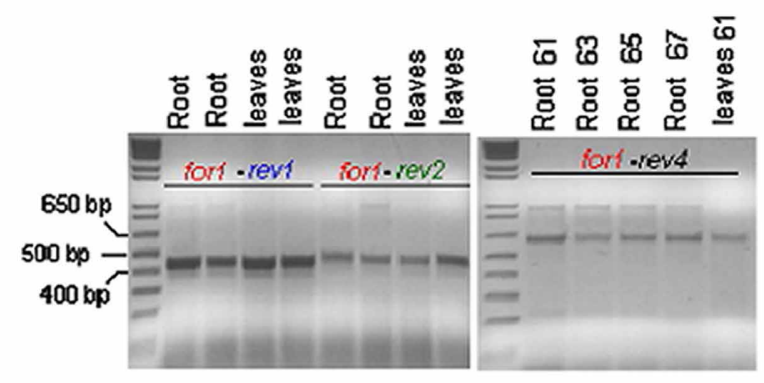

FIGURE 5 | Gene and predicted coding sequence of cucumber ferritin protein XP004163524 (reported at NCBI as ferritin-3, chloroplastic-like, transcript variant 1, LOC101221012). (A) IDRS-like sequence in gene promoter is highlighted in yellow; ATG start is in red color; exons are highlighted in gray. Positions of primers Cucsafor1 (in red), Cucsarev1 (in blue), Cucsarev2 (in green), Cucsarev4 (in black) are underlined; (B) left panel: RT-PCR reactions with primer pairs Cucsafor1-Cucsa-rev1 and
Cucsafor1-Cucsa-rev2, with either two independent RNA extracts from Fe-excess cucumber roots or two independent RNA extracts from Fe-excess leaves. The Kb ladder Plus (Invitrogen) has been loaded in the far left lane. Right panel: RT-PCR reactions with primer pair Cucsafor1-Cucsa-rev4, with RNA purified from Fe-excess roots at 61, 63, 65,67 anneal. temp., or with RNA purified from Fe-excess leaves at $61^{\circ} \mathrm{C}$ anneal. temp. 
fact that mitochondria are strongly affected by Fe deficiency, they in fact display a high level of functional flexibility, which allows them to guarantee cell viability under $\mathrm{Fe}$ shortage (Vigani, 2012).

The present work confirms the localization of the ferritin in mitochondria of cucumber roots, as already observed in Arabidopsis and pea (Zancani et al., 2004; Tarantino et al., 2010a,b); its abundance is strictly dependent on the total Fe content in mitochondria which, in turn, is dependent on the availability of $\mathrm{Fe}$ in the growth medium.

A unique mRNA transcribed from LOC101221012 cucumber gene, coding for the ferritin protein named alternatively Csa5M215130 or XP_004163524 by two different sequencing consortia ( $\mathrm{Li}$ et al., 2011; Wóycicki et al., 2011) has been identified in Fe-excess cucumber roots and leaves; moreover, such mRNA is $100 \%$ identical to the primary transcript of the ferritin gene named Cucsa144440 in the Phytozome hub (Goodstein et al., 2012). Results in the present work show that a single Fe-dependent ferritin isoform, named Csa5M215130/XP_004163524 accumulates in cucumber roots. Since no other transcripts are detected in green leaves of Fe-excess cucumber plants, such ferritin protein is most probably dualtargeted to both chloroplasts and mitochondria and represents an example of the so-called "ambiguous targeting" (Peeters and Small, 2001; Carrie and Small, 2013).

The presence, in LOC101221012/Cucsa144440 gene promoter ferritin, of an IDRS-like stretch, is suggestive of a common regulatory mechanism for the Fe-dependent expression of the two ferritin genes in Arabidopsis and in cucumber.

\section{REFERENCES}

Arnaud, N., Murgia, I., Boucherez, J., Briat, J. F., Cellier, F., and Gaymard, F. (2006). An ironinduced Nitric Oxide burst precedes ubiquitin-dependent protein degradation for Arabidopsis AtFerl ferritin gene expression. J. Biol. Chem. 281, 23579-23588. doi: 10.1074/jbc.M602135200

Arosio, P., Ingrassia, R., and Cavadini, P. (2009). Ferritins: a family of molecules for iron storage, antioxidation and more. Biochim. Biophys. Acta 1790, 589-599. doi: 10.1016/j.bbagen.2008.09.004

Balk, J., and Leaver, C. J. (2001). The PET1-CMS mitochondrial mutation in sunflower is associated with premature programmed cell death and cytochrome c release. Plant Cell 13, 1803-1818.

Balk, J., Leaver, C. J., and McCabe, P. F. (1999). Translocation of cytochrome $c$ from the mitochondria to the cytosol occurs during heat-induced programmed cell death in cucumber plants. FEBS Lett. 463, 151-154. doi: 10.1016/S0014-5793(99)01611-7

Balk, J., Pierik, A. J., Netz, D. J. A., Mühlenhoff, U., and Lill, R.
(2004). The hydrogenase-like Narlp is essential for maturation of cytosolic and nuclear ironsulphur proteins. EMBO J. 23, 2105-2115. doi: 10.1038/sj.emboj. 7600216

Berglund, A. K., Spanning, E., Biverstahl, H., Maddalo, G., Tellgren-Roth, C., Maler, L., et al. (2009). Dual targeting to mitochondria and chloroplasts: characterization of Thr-tRNA synthetase targeting peptide. Mol. Plant 2, 1298-1309. doi: $10.1093 / \mathrm{mp} / \mathrm{ssp} 048$

Briat, J. F., Duc, C., Ravet, K., and Gaymard, F. (2009). Ferritins and iron storage in plants. Biochem. Biophys. Acta 1800, 806-814. doi: 10.1016/j.bbagen.2009.12.003

Briat, J. F., Ravet, K., Arnaud, N., Duc, C., Boucherez, J., Touraine, B., et al. (2010). New insights into ferritin synthesis and function highlight a link between iron homeostasis and oxidative stress in plants. Ann. Bot. 105, 811-822. doi: 10.1093/aob/mcp128

Camacho-Pereira, J., Meyer, L. E., Machado, L. B., Oliveira, M. F., and Galina, A. (2009). Reactive oxygen species production by potato

The results shown in the present work strongly suggest that the detected multimer complex is truly the 24-mer ferritin complex Csa5M215130/XP_004163524; indeed, as observed for the monomer, the abundance of the multimer complex is also dependent on the mitochondrial $\mathrm{Fe}$ content and results obtained in native gel are consistent with its expected weight (around $600 \mathrm{KDa}$ ).

In conclusion, for the first time proof that ferritin is a functional Fe-storage protein in cucumber mitochondria is provided: the 24-mer ferritin complex indeed truly binds Fe(III).

Such results open the way to further investigations about the possible physiological relevance of ferritin as a root protectant against various oxidative stresses which may arise during adverse field conditions.

\section{ACKNOWLEDGMENTS}

We are grateful to P. Arosio and co-workers for providing recombinant human ferritin and for support during preliminary experiments and to R. B. Klösgen and M. Jakob for providing Toc33. Gianpiero Vigani and Irene Murgia were supported by FIRB 2012 (MIUR, RBFR127WJ9).

\section{SUPPLEMENTARY MATERIAL}

The Supplementary Material for this article can be found online at: http://www.frontiersin.org/Plant_Nutrition/ 10.3389/fpls.2013.00316/abstract

Figure S1 | Predicted coding sequence for XP004163525 protein.

Figure S2 | Predicted coding sequence for XP_004148174 protein.

tuber mitochondria is modulated by mitochondrially bound hexokinase activity. Plant Physiol. 146, 1099-1110.

Campanella, A., Rovelli, E., Santambrogio, P., Cozzi, A., Taroni, F., and Levi, S. (2009). Mitochondrial ferritin limits oxidative damage regulating mitochondrial iron availability: hypothesis for a protective role in Friedreich ataxia. Hum. Mol. Genet. 18, 1-11. doi: 10.1093/hmg/ ddn 308

Carrie, C., and Small, I. (2013). A revaluation of dual-targeting of proteins to mitochondria and chloroplasts. Biochim. Biophys. Acta 1833, 253-259. doi: 10.1016/j.bbamcr.2012.05.029

Claros, M. G., and Vincens, P. (1996). Computational methods to predict mitochondrially imported proteins and their targeting sequences. Eur. J. Biochem. 241, 779-786. doi: 10.1111/j.1432-1033. 1996.00779.x

Conte, S. S., and Walker, E. L. (2011). Transporter contributing to iron trafficking in plants. Mol. Plant 4, 464-476. doi: 10.1093/mp/ ssr015
Corpet, F. (1988). Multiple sequence alignment with hierarchical clustering. Nucleic Acids Res. 16, 10881-10890. doi: 10.1093/nar/16. 22.10881

Emanuelsson, O., Brunak, S., von Heijne, G., and Nielsen, H. (2007). Locating proteins in the cell using TargetP, SignalP, and related tools. Nat. Protoc. 2, 953-971. doi: 10.1038/nprot.2007.131

Goodstein, D. M., Shu, S., Howson, R., Neupane, R., Hayes, R. D. Fazo, J., et al. (2012). Phytozome: a comparative platform for green plant genomics. Nucleic Acids Res. 40, D1178-D1186. doi: 10.1093/ nar/gkr944

Grierson, C. S., Barnes, S. R., Chase, M. W., Clarke, M., Grierson, D., Edwards, K. J., et al. (2011). One hundred important questions facing plant science research. New Phytol. 192, 6-12. doi: 10.1111/j.1469-8137.2011.03859.x

Huang, S., Li, R., Zhang, Z., Li, L., Gu, X., Fan, W., et al. (2009). The genome of the cucumber Cucumis sativus L. Nat. Genet. 41, 1275-1281. doi: 10.1038/ng.475

Kobayashi, T., and Nishizawa, N. K. (2012). Iron uptake, translocation, 
and regulation in higher plants. Ann. Rev. Plant Biol. 63, 131-152. doi: $\quad 10.1146 /$ annurev-arplant042811-105522

Landsberg, E. C. (1986). Function of rhizodermal transfer cells in the $\mathrm{Fe}$ stress response mechanism of Capsicum annuum L. Plant Physiol. 82, 511-517. doi: 10.1104/pp.82.2.511

Levi, S., Corsi, B., Bosisio, M., Invernizzi, R., Volz, A., Sanford, D., et al. (2001). A human mitochondrial ferritin encoded by an intronless gene. J. Biol. Chem. 276, 24437-24440. doi: 10.1074/jbc.C100141200

Li, Z., Zhang, Z., Yan, P., Huang, S., Fei, Z., and Lin, K. (2011). RNA-Seq improves annotation of protein-coding genes in the cucumber genome. BMC Genomics 12:540. doi: 10.1186/1471-2164-12-540

Lichtenthaler, H. K. (1987). Chlorophyll and carotenoids: pigments of photosynthetic biomembranes. Methods Enzymol. 148, 350-382. doi: 10.1016/00766879(87)48036-1

Luscieti, S., Santambrogio, P., Langlois d'Estaintot, B., Granier, T., Cozzi, A., Poli, M., et al. (2010). Mutant ferritin L-chains that cause neurodegeneration act in a dominant-negative manner to reduce ferritin iron incorporation. J. Biol. Chem. 285, 11948-11957. doi: 10.1074/jbc.M109.096404

Murgia, I., Arosio, P., Tarantino, D., and Soave, C. (2012). Crops biofortification for combating "hidden hunger" for iron. Trends Plant Sci. 17, 47-55. doi: 10.1016/j.tplants. 2011.10.003

Murgia, I., Delledonne, M., and Soave, C. (2002). Nitric oxide mediates iron-induced ferritin accumulation in Arabidopsis. Plant J. 30, 521-528. doi: 10.1046/j.1365-313X.2002.01312.x

Murgia, I., Tarantino, D., and Soave, C. (2009) Mitochondrial iron metabolism in plants: frataxin comes into play. Plant Soil 325, 5-14. doi: 10.1007/s11104-0090038-6

Murgia, I., Vazzola, V., Tarantino, D., Cellier, F., Ravet, K., Briat, J. F., et al. (2007). Knock-out of the ferritin AtFerl causes earlier onset of age-dependent leaf senescence in Arabidopsis. Plant Physiol. Biochem. 45, 898-907. doi: 10.1016/j.plaphy.2007.09.007

Nakai, K., and Kanehisa, M. (1991) Expert system for predicting protein localization sites in gram-negative bacteria. Proteins 11, 95-110. doi: 10.1002/prot.340110203

Peeters, N., and Small, I. (2001) Dual targeting to mitochondria and chloroplasts. Biochim. Biophys. Acta 1541, 54-63. doi: 10.1016/S0167-4889(01)00146-X

Petit, J. M., van Wuytswinkel, O., Briat, J. F., and Lobreaux, S. (2001). Characterization of an irondependent regulatory sequence involved in the transcriptional control of AtFerl and ZmFer1 plant ferritin genes by iron. J. Biol. Chem. 276, 5584-5590. doi: 10.1074/jbc.M005903200

Pujol, C., Marechal-Drouard, L., and Duchene, A. M. (2007) How can organellar protein N-terminal sequences be dual targeting signals? In silico analysis and mutagesis approach. J. Mol. Biol. 369, 356-367. doi: 10.1016/j.jmb.2007.03.015

Ramirez, L., Simontacchi, M., Murgia, I., Zabaleta, E., and Lamattina, L. (2011). Nitric Oxide, Nitrosyl Iron complexes, ferritin and frataxin: a well equipped team to preserve plant iron homeostasis. Plant Sci. 181, 582-592. doi: 10.1016/j.plantsci.2011.04.006

Rödiger, A., Baudisch, B., and Klosgen, R. B. (2010). Simultaneous isolation of intact mitochondria and chloroplast from a single pulping of plant tissue. J. Plant Physiol. 167, 620-624. doi: 10.1016/j.jplph.2009.11.013

Sutak, R., Seguin, A., Garcia-Serres, R., Oddou, J. L., Dancis, A., Tachezy, J., et al. (2012). Human mitochondrial ferritin improves respiratory function in yeast mutants deficient in iron-sulfur cluster biogenesis, but is not a functional homologue of yeast frataxin. Microbiologyopen 1, 95-104. doi: 10.1002/mbo3.18

Tarantino, D., Casagrande, F., Soave, C., and Murgia, I. (2010a). Knocking out of the mitochondrial AtFer4 ferritin does not alter response of Arabidopsis plants to abiotic stresses. J. Plant Physiol. 167, 453-460. doi: 10.1016/j.jplph.2009.10.015

Tarantino, D., Santo, N., Morandini, P., Casagrande, F., Braun, H. P., Heinemeyer, J., et al. (2010b). AtFer4 ferritin is a determinant of iron homeostasis in Arabidopsis thaliana heterotrophic cells. J. Plant Physiol. 167, 1598-1605. doi: 10.1016/j.jplph.2010.06.020

Thomine, S., and Vert, G. (2013). Iron transport in plants: better safe than sorry. Curr. Opin. Plant Biol. 6, 1-6.

Vigani, G. (2012). Discovering the role of mitochondria in the iron deficiency-induced metabolic responses of plants. J. Plant Physiol. 169, 1-11. doi: 10.1016/j.jplph.2011.09.008

Vigani, G., Chittò, A., De Nisi, P., and Zocchi, G. (2012). cDNAAFLP analysis reveals a set of new genes differentially expressed in response to $\mathrm{Fe}$ deficiency in cucumber (Cucumis sativus L.) root apexes. Biol. Plant 56, 502-508. doi: 10.1007/s10535-012-0050-1

Vigani, G., Maffi, D., and Zocchi, G. (2009). Iron availability affects the function of mitochondria in cucumber roots. New Phytol. 182, 127-136. doi: 10.1111/j.1469-8137.2008.02747.x

Vigani, G., Zocchi, G., Bashir, K. Philippar, K., and Briat, J. F. (2013a). Signal from chloroplasts and mitochondria for iron homeostasis regulation. Trends Plant Sci. 18, 305-311. doi: 10.1016/j.tplants. 2013.01.006

Vigani, G., Morandini, P., and Murgia, I. (2013b). Searching iron sensors in plants by exploring the link among $2^{\prime} \mathrm{OG}$-dependent dioxygenases, the iron deficiency response and metabolic adjustments occurring under iron deficiency. Front. Plant Sci. 4:169. doi: 10.3389/fpls. 2013.00169

Vigani, G., and Zocchi, G. (2010). Effect of $\mathrm{Fe}$ deficiency on mitochondrial alternative $\mathrm{NAD}(\mathrm{P}) \mathrm{H}$ dehydrogenases in cucumber roots. J. Plant Physiol. 167, 666-669. doi: 10.1016/j. jplph.2009.12.006

Wang, L., Yang, H., Zhao, S., Sato, H., Konishi, Y., Beach, T. G., et al.
(2011). Expression and localization of mitochondrial ferritin mRNA in Alzheimer's Disease cerebral cortex. PLoS ONE 6:e22325. doi: 10.1371/journal.pone.0022325

Winterbourn, C. C. (1995). Toxicity of iron and hydrogen peroxide: the Fenton reaction. Toxicol. Lett. 82/83, 969-974. doi: 10.1016/03784274(95)03532-X

Wóycicki, R., Witkowicz, J., Gawroński, P., Dąbrowska, J., Lomsadze, A., Pawełkowicz, M., et al. (2011). The genome sequence of the NorthEuropean cucumber (Cucumis sativus L.) unravels evolutionary adaptation mechanisms in plants. PLoS ONE 6:e22728. doi: 10.1371/journal.pone.0022728

Zancani, M., Peresson, M., Biroccio, A., Federici, G., Urbani, A., Murgia, I., et al. (2004). Evidence for the presence of ferritin in plant mitochondria. Eur. J. Biochem. 271, 3657-3664. doi: 10.1111/j.14321033.2004.04300.x

Conflict of Interest Statement: The authors declare that the research was conducted in the absence of any commercial or financial relationships that could be construed as a potential conflict of interest.

Received: 23 May 2013; accepted: 28 July 2013; published online: 16 August 2013. Citation: Vigani G, Tarantino D and Murgia I (2013) Mitochondrial ferritin is a functional iron-storage protein in cucumber (Cucumis sativus) roots. Front. Plant Sci. 4:316. doi: 10.3389/fpls. 2013.00316

This article was submitted to Plant Nutrition, a section of the journal Frontiers in Plant Science.

Copyright (c) 2013 Vigani, Tarantino and Murgia. This is an open-access article distributed under the terms of the Creative Commons Attribution License (CC BY). The use, distribution or reproduction in other forums is permitted, provided the original author(s) or licensor are credited and that the original publication in this journal is cited, in accordance with accepted academic practice. No use, distribution or reproduction is permitted which does not comply with these terms. 